\title{
Potential roles of decidual prolactin in early pregnancy
}

\author{
Henry N. Jabbour and Hilary O. D. Critchley \\ MRC Human Reproductive Sciences Unit and Obstetrics and Gynaecology, \\ Department of Reproductive and Development Sciences, Centre for Reproductive Biology, \\ 37 Chalmers Street, Edinburgh EH3 9ET, UK
}

\begin{abstract}
Successful establishment of pregnancy is dependent on uterine receptivity at the time of trophoblast invasion and implantation. The endometrium undergoes morphological and functional differentiation during the mid- to late secretory phase of the menstrual cycle in preparation for such an event. These changes are orchestrated by ovarian steroid hormones. However, local autocrine-paracrine signalling at the deciduo-placental interface is crucial for successful establishment of pregnancy. One key cytokine that may regulate many functions in implantation is prolactin. Prolactin is secreted by the decidualized endometrium at the time of predicted conception and, in the event of pregnancy, local expression and secretion of prolactin persists until term. Prolactin mediates its effect on target cells through interaction with single-pass transmembrane receptors. Localization of the sites of expression of the prolactin receptor indicates that the cytokine may regulate an array of functions in the pregnant uterus that are crucial in implantation and early pregnancy.
\end{abstract}

The successful establishment of pregnancy is dependent on proper embryo development and uterine receptivity. The latter consists of differentiation and secretory transformation of the glandular epithelial cells followed by decidualization of the stromal compartment during the mid- to late secretory phase of the menstrual cycle. This period is also characterized by extensive tissue remodelling in the superficial layer of the endometrium in preparation for the invasion and implantation of the proliferating trophoblast cells. The regulation of local events critical for decidualization and tissue remodelling in normal implantation remains poorly defined. Only with this information will progress be possible in the management of situations in which these physiological events are dysfunctional. Specifically, in the context of the present review, if mechanisms governing normal implantation are suboptimal the establishment of an early pregnancy may be impaired. Impaired early pregnancy development and consequently uteroplacental function may be associated not only with miscarriage but also with later pregnancy complications including pre-eclampsia and intrauterine growth restriction (Miller et al., 1980; Wilcox et al., 1988). A direct role for impaired decidualization in pregnancy failure is emphasized in women with recurrent miscarriage. A subgroup of these women has a prevalence of antiphospholipid antibodies in their sera, which has been causatively associated with pregnancy failure. More recently, it has been suggested that antiphospholipid antibodies compromise

Email: h.jabbour@hrsu.mrc.ac.uk pregnancy outcome in these women by perturbing decidualization of endometrial stromal cells and inhibiting prolactin secretion (Pierro et al., 1999).

\section{Regulation of morphological and functional changes in the endometrium throughout the menstrual cycle and early pregnancy}

The endometrium is composed of two layers: an upper functional layer, which is shed, and an underlying basal layer, which regenerates after menstruation. Cyclical changes are apparent in the glandular, stromal and vascular components of the endometrium and these changes are regulated by sequential production of oestrogen and progesterone from the ovary (reviewed in Critchley and Healy, 1998). During the menstrual phase (first 4 days of bleeding) there is histological evidence of subepithelial necrosis and glandular collapse. From day 3 after the onset of bleeding, cellular regeneration commences in the glandular and stromal tissues under the influence of oestrogen. This period is termed the proliferative phase and extends between day 4 after the onset of bleeding and ovulation. After ovulation, the secretory phase of the menstrual cycle commences, which is dominated by progesterone. Glandular secretions are maximally evident during the mid-secretory phase (days 5-9 after ovulation), and in the late secretory phase (from day 10 after ovulation until menstruation) pre-decidual changes take place in the stromal compartment.

Oestrogen and progesterone act sequentially to regulate the cellular concentrations of sex steroid receptors in the uterus (Lessey et al., 1988). In the non-pregnant 
endometrium, both the classic oestrogen receptor $\alpha$ and progesterone receptors increase in the nuclei of the glands and stroma during the proliferative phase. In the secretory phase, both oestrogen receptor $\alpha$ and progesterone receptors decline in the glandular compartment of the endometrium. In contrast, expression of the progesterone receptor persists in the endometrial stromal compartment and is particularly evident in the perivascular tissues. Both oestrogen and progesterone receptors exist in more than one isoform (Tung et al., 1993; Enmark et al., 1997). A novel oestrogen receptor isoform, oestrogen receptor $\beta$, was cloned from a rat prostate cDNA library (Kuiper et al., 1996). Oestrogen receptor $\beta$ is expressed in uterine tissue; however, to date, detailed spatio-temporal studies of oestrogen receptor $\beta$ expression in human endometrium have not been published. Both isoforms of the progesterone receptor (the short $\mathrm{A}$ and long $\mathrm{B}$ isoforms) are expressed in the stromal and glandular compartments during the proliferative phase. However, in the secretory phase and early pregnancy, progesterone receptor A isoform predominates in the stromal compartment (Wang et al., 1998). It is not possible to raise antibodies specific to progesterone receptor $\mathrm{A}$ and hence the $\mathrm{A}$ isoform is assumed to be the subtype responsible for positive immunostaining when the progesterone receptor B isoform cannot be detected specifically (Fig. 1). Whether the effects of progesterone on endometrial differentiation in the secretory phase and early pregnancy are mediated mainly by progesterone receptor A remains to be elucidated.

\section{Regulation of uterine decidualization}

Decidualization is a crucial step in the initiation and establishment of pregnancy and is a feature of species that show invasive haemochorial placentation. The most obvious role of the decidualized endometrium is to provide a nutritive environment for the developing fetus throughout pregnancy. In humans, decidualization is independent of the presence of a blastocyst and early signs of predecidual changes are first observed in stromal cells close to vascular structures in the mid- to late secretory phase of the menstrual cycle. When implantation is successful, glandular secretory activity continues, although towards the end of the first trimester the glands are less active. In vivo, decidualization is controlled most effectively by progesterone acting on an oestradiol-primed uterus and this process can be induced as a consequence of administration of exogenous progestins (Critchley et al., 1998). However, the cellular interactions and progesterone target genes that are involved in decidualization are complex and still poorly outlined. A host of growth factors, cytokines and protein hormones are also recognized as crucial signals for the initiation and maintenance of decidualization. Examples include epidermal growth factor, insulin-like growth factor (IGF), IGF binding protein 1, prostaglandins, relaxin and tissue factor (reviewed in Osteen, 1999).

Decidualization can be induced in vitro in cultured en- dometrial stromal cells. However, in such a model system, progesterone acts as a weak inducer of decidualization (Daly et al., 1983). In vitro, decidualization of endometrial stromal cells can be initiated in the absence of progesterone by factors that increase intracellular CAMP concentrations. These factors include prostaglandin $\mathrm{E}$, relaxin, corticotrophin-releasing hormone, gonadotrophins or cAMP analogues such 8-bromo-cAMP (Frank et al., 1994; Lane et al., 1994; Ferrari et al., 1995; Telgmann et al., 1997; Nemansky et al., 1998; Brosens et al., 1999). Induction of expression of the decidual prolactin gene in vitro is often used as a marker of decidualization of endometrial stromal cells (Irwin et al., 1989).

\section{Prolactin expression in the decidualized endometrium and its regulation}

Prolactin is one of the major proteins synthesized and secreted during decidualization of the human endometrial stroma in vivo (Maslar and Riddick, 1979). In the nonpregnant uterus, prolactin synthesis is detected between the mid-secretory phase and menses and coincides with the first histological signs of decidualization (Fig. 2). In the event of pregnancy, decidual prolactin secretion increases steadily after implantation, reaching a peak at about weeks 20-25 of pregnancy, and declines towards term (Wu et al., 1995). Increased prolactin synthesis by the decidua is correlated with an increase in the size of decidual cells and increased prolactin concentrations in the amniotic fluid (Wu et al., 1995). Prolactin synthesized de novo by decidual cells is indistinguishable from pituitary prolactin by chemical, immunological and biological criteria (Tomita et al., 1982). Moreover, the amino acid encoding sequence is identical for both pituitary and decidual prolactin (Takahashi et al., 1984). However, the decidual RNA transcript is longer than its pituitary counterpart, differing in the $5^{\prime}$ untranslated region (Gellersen et al., 1989). Comparative analysis of the decidual and pituitary RNA transcripts has revealed the utilization of alternative promoter regions of transcription, thus accounting for tissue-specific hormonal regulation of expression of the prolactin gene in the decidua and pituitary (Gellersen et al., 1994). The transcription initiation site in the decidua is located approximately $5.7 \mathrm{~kb}$ upstream of the pituitaryspecific cap site (Gellersen et al., 1994). Tissue-specific regulation of prolactin gene expression is supported further by the observation that pituitary prolactin expression is dependent on the transcription factor Pit-1 (Ingraham et al., 1990). However, Pit-1 is not expressed in the uterus (Rhodes et al., 1994) and has no effect on transcription of the decidual prolactin promoter despite the presence of two binding motifs for Pit-1 (Gellersen et al., 1994). Moreover, classic regulators of pituitary prolactin secretion (bromocriptine, dopamine, thyrotropin releasing hormone, oestrogen) have no effect on the expression of prolactin in human decidual tissue (Huang et al., 1987).

Prolactin expression is controlled most effectively in the 


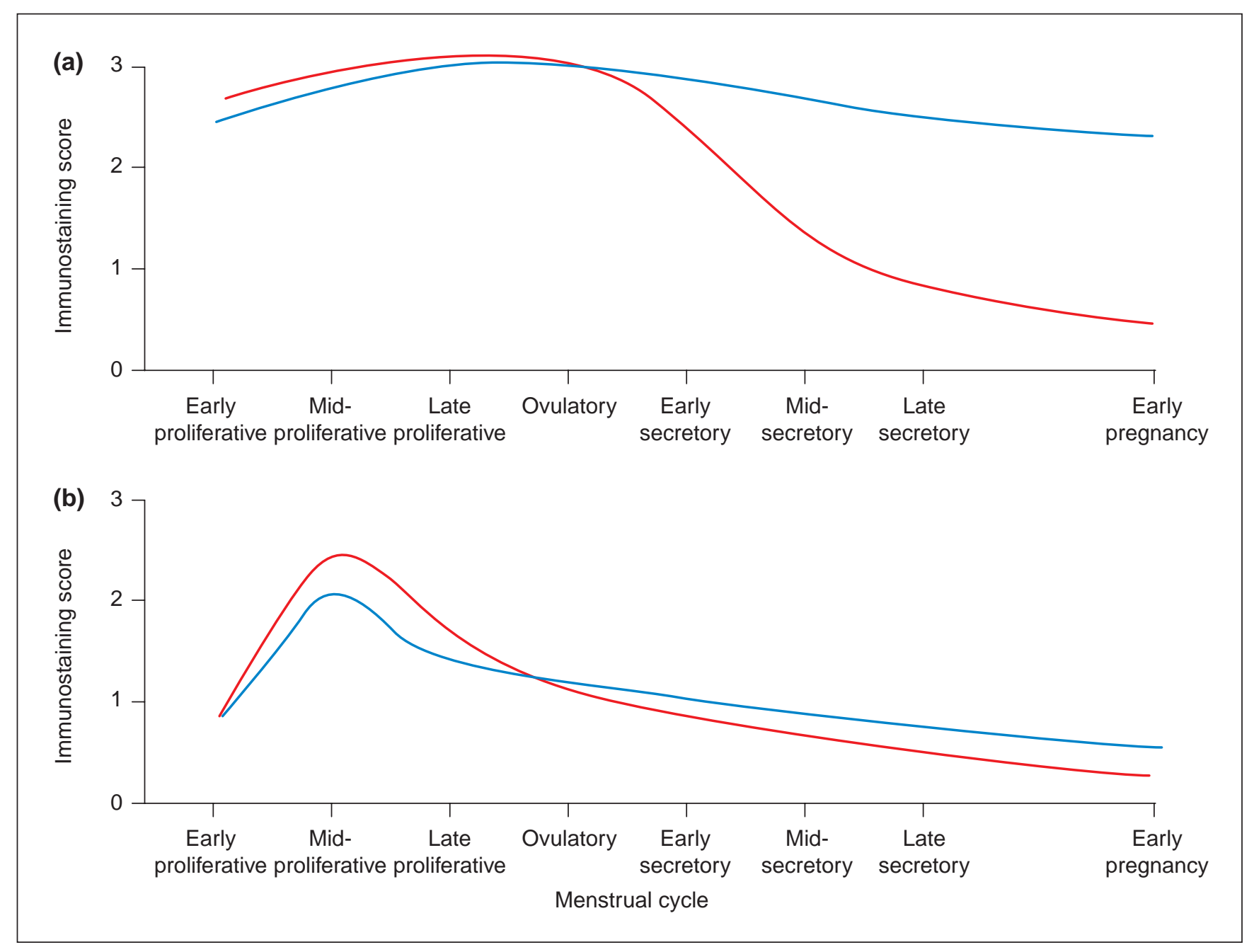

Fig. 1. Schematic representation of progesterone receptor (A and B isoforms) immunostaining scores in the endometrial glands (red) and stroma (blue) throughout the menstrual cycle. Subjective immunostaining score $0-3(0=$ no immunostaining, $3=$ intense immunostaining). (a) Immunostaining for progesterone receptor A and B is at a maximum in endometrial glands and stroma during the proliferative phase and decreases in the secretory phase in the glandular compartment. (b) Immunostaining for progesterone receptor B is at a maximum during the mid- to late proliferative phase and decreases in both endometrial glands and stroma during the secretory phase of the menstrual cycle. Progesterone receptor A is assumed to be the subtype responsible for positive staining when progesterone receptor B isoform cannot be detected specifically. By inference only the progesterone receptor A subtype is expressed strongly in decidualized stromal cells in the secretory phase and early pregnancy. (Data derived from Wang et al., 1998.)

decidualized endometrium by progesterone. In the presence of progesterone, decidualized endometrium secretes prolactin at increasing concentrations and in its absence prolactin secretion ceases within 2-3 days (Maslar and Ansbacher, 1986). Moreover, prolactin expression in secretory endometrium is high after in vivo administration of medroxyprogesterone acetate (Reis et al., 1999) and in vivo administration of the antiprogestin RU486 significantly reduces prolactin expression in the decidualized stromal cells (Wang et al., 1994). However, evidence indicates that although progesterone is important for inducing and maintaining decidualization, it does not induce prolactin gene expression directly. This hypothesis can be inferred from the absence of co-localization of at least genomic progesterone receptors in prolactin secreting cells (Wang et al., 1994) and the inability of activated progesterone receptors (both $\mathrm{A}$ and $\mathrm{B}$ isoforms) to induce transcription of the decidual prolactin promoter (Gellersen et al., 1994). Other factors shown to increase prolactin expression in long-term cultures of human endometrial stromal cells include relaxin and insulin-like growth factor I (IGF-I), both of which are synthesized locally by the stromal cells (Rosenberg et al., 1991).

Induction of decidual prolactin expression is linked to the 


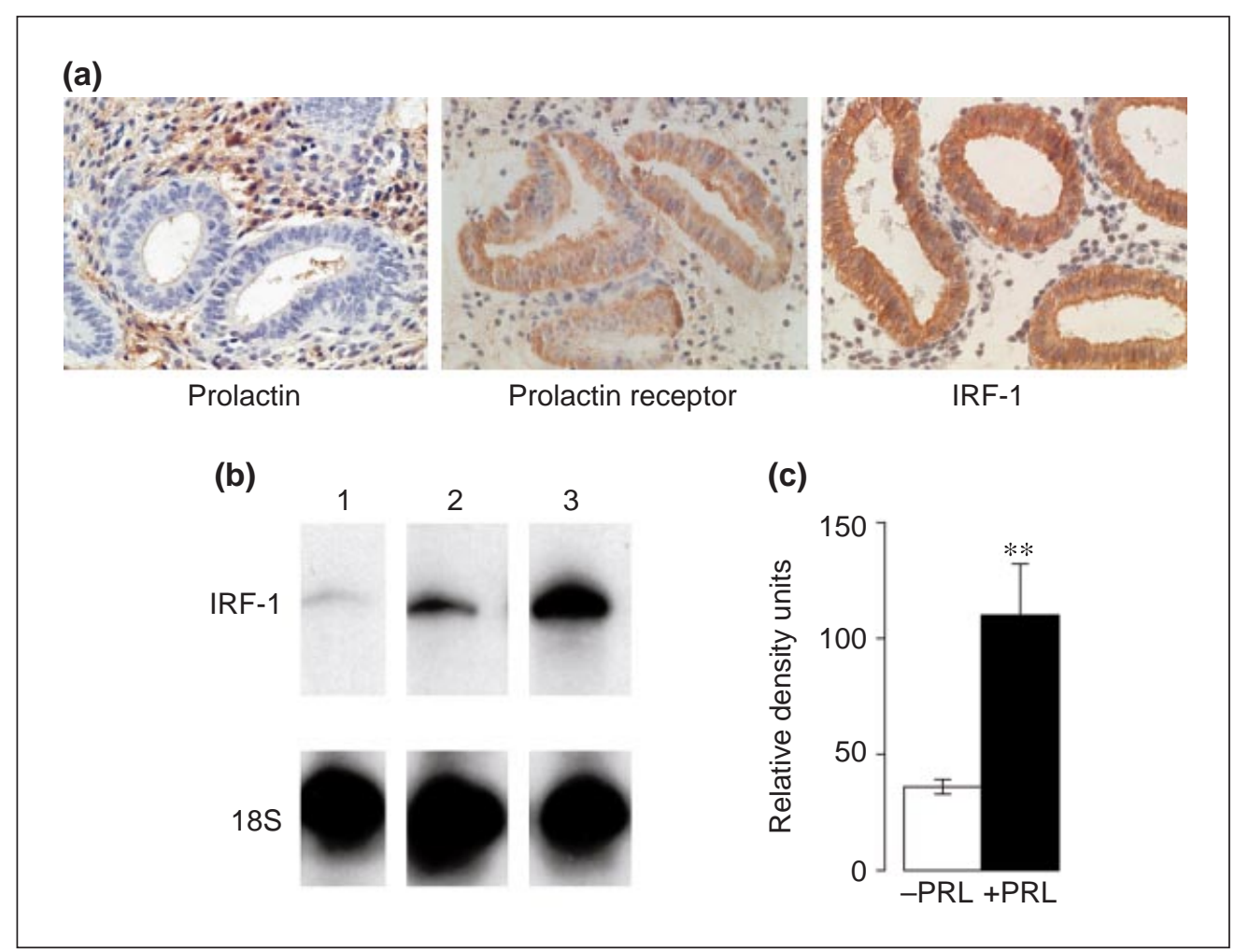

Fig. 2. Immunohistochemical localization of prolactin, prolactin receptor and interferon regulatory factor 1 (IRF-1) in human endometrium collected during the mid- to late secretory phase of the menstrual cycle. (a) Prolactin is localized to the stromal compartment, whereas prolactin receptors and IRF-1 are co-localized in the glandular epithelial cells. $(b, c)$ These figures demonstrate the effect of prolactin on expression of IRF-1 in the human endometrium. (b) Ribonuclease protection assay of IRF1 in secretory phase human endometrium after culture for $2 \mathrm{~h}$ in the absence (lane 2) or presence (lane 3) of $100 \mathrm{ng}$ human prolactin $\mathrm{ml}^{-1}$. Lane 1 is control RNA from tissue collected at the start of the experiment and is used to calculate background IRF-1 expression. 18S ribosomal RNA was used to correct for loading variation in the RNA between treatments. (c) The relative density units of IRF-1 expression in human endometrium $(n=3)$ after culture as outlined in (b). The relative density units for IRF-1 expression are higher $(* * P<0.01)$ after culture with prolactin for $2 \mathrm{~h}$. (Reproduced with permission from The Endocrine Society; Jabbour et al., 1998, 1999.)

CAMP-protein kinase A signalling pathway (reviewed in Telgmann and Gellersen, 1998). cAMP alone can induce prolactin production in endometrial monolayers and this effect is synergistically enhanced by medroxyprogesterone acetate (Brosens et al., 1999). Moreover, 8-Br-cAMP can strongly activate the transcription of the decidual prolactin promoter in transfected endometrial stromal cells and this effect is further enhanced with medroxyprogesterone acetate (Gellersen et al., 1994; Brosens et al., 1999). Treatment with medroxyprogesterone acetate alone has minimal effect on transcription of the decidual prolactin promoter (Gellersen et al., 1994; Brosens et al., 1999). These data indicate that a ligand linked to CAMP is a major regulator of prolactin expression in the decidualized endometrium during the late secretory phase of the menstrual cycle and that the CAMPprotein kinase pathway may sensitize the endometrial stromal cells to the effects of progestins (Brosens et al., 1999). In turn, progestins may act synergistically with cAMP to stabilize the decidual prolactin transcript (Gellersen et al., 1994). More recently, Pohnke et al. (1999) have demonstrated that the effect of CAMP on transcription of the decidual prolactin promoter is mediated via the CCAAT/enhancer binding proteins (C/EBP). C/EBP consensus binding sequences are present in the decidual prolactin promoter and mutation of these sites abrogates the cAMP-mediated activation of the decidual prolactin promoter.

\section{Prolactin receptor signalling and its expression in the endometrium}

Prolactin mediates its effect on target cells via single-pass transmembrane-spanning receptors that belong to the class 1 family of cytokine receptors. Different membrane-bound isoforms of the prolactin receptor, termed short and long, 
have been identified in vivo in rodent and ruminant species (reviewed in Kelly et al., 1991; Bignon et al., 1997). These isoforms possess similar extracellular domains comprising 210 amino acids but differ essentially in the length of the cytoplasmic domain. More recently, in vivo expression of two isoforms of the receptor, termed long and intermediate, has been described in humans (Kline et al., 1999). The intermediate form results from a deletion at a consensus splice site resulting in a frame shift and a truncated intracytoplasmic domain; both forms of the receptor share identical extracellular domains and bind prolactin with similar affinities (Kline et al., 1999). The two isoforms are co-expressed in a large array of human tissues although the physiological significance of each of the isoforms remains to be elucidated. It has been suggested that the co-expression of different receptor isoforms in the same type of cell may modulate the function of prolactin on target cells through formation of inactive receptor heterodimers. Receptor dimerization is an essential component of prolactin receptor signalling and it has been demonstrated that, at least in rodent species, the short form of the receptor can block signalling of the long form of the receptor to a prolactinresponsive promoter (Berlanga et al., 1997). Whether the intermediate form of the human prolactin receptor acts in a similar manner is yet to be established.

It is also plausible that co-expression of the different receptor isoforms may be a mechanism for conveying multi-prolactin receptor effects on target cells through a diversity of signalling cascades that may be receptor isoform-specific. Prolactin signals its effect to target promoters through interaction with protein tyrosine kinases such as p59 fyn and p120jak2 and activation of different Stat (signal transducers and activators of transcription) proteins. The Stat proteins dimerize and initiate transcription of prolactin responsive genes including interferon regulatory factor 1 , $\beta$-casein and $\alpha_{2}$-macroglobulin (reviewed in Yu-Lee, 1997). Prolactin receptor dimerization also initiates the mitogen-activated protein kinase (MAPK) signalling cascade (Das and Vonderhaar, 1995), leading to activation of transcription factors necessary for cell cycle progression including Myc, Jun and T-cell factor (Seth et al., 1992). Evidence indicates that these signalling cascades are activated differentially by the different receptor isoforms and hence may mediate specific prolactin signals in the target cells. For instance, in humans, both the long and intermediate forms of the prolactin receptor activate Jak2, whereas only the long form activates Fyn (Kline et al., 1999).

Prolactin receptor expression has been characterized in the human uterus throughout the menstrual cycle and pregnancy. Prolactin receptor expression in the human endometrium is temporally regulated throughout the menstrual cycle. Minimal expression is detected during the proliferative phase and expression is upregulated during the mid- to late secretory phase (Jabbour et al., 1998; Jones et al., 1998). Prolactin receptor expression in the non-pregnant human endometrium is localized predominantly to the glandular epithelial cells (Fig. 2; Jabbour et al., 1998). In the event of pregnancy, prolactin receptor expression is maintained and is localized to the decidua, chorionic cytotrophoblast, amniotic epithelium and placental syncytiotrophoblast (Maaskant et al., 1996). Evidence indicates that both the long and intermediate forms of the receptor are expressed in the uterus and other tissues such as the placenta (Kline et al., 1999). However, the temporal pattern and site of expression of the different receptor isoforms and their potential function in uterine physiology and pregnancy remain to be elucidated. Prolactin receptor expression has also been detected in the non-pregnant uterus of other primate species such as baboons and marmosets (Frasor et al., 1999; Dalrymple and Jabbour, 2000) and throughout pregnancy in baboons (Frasor et al., 1999).

Prolactin function in the human endometrium is linked to the Jak2/Stat signalling pathway. Jak2, Stat1 and Stat5 proteins are rapidly phosphorylated after stimulation of the glandular epithelial cells with prolactin (Jabbour et al., 1998). The phosphorylated Stat proteins subsequently translocate to the nucleus and initiate the transcription of prolactin-responsive genes. One prolactin target gene we have identified recently in the human glandular epithelial cells is the transcription factor, interferon regulatory factor 1 (IRF-1). IRF-1 co-localizes with prolactin receptors in the glandular compartment of the endometrium and IRF-1 expression in the late secretory phase endometrium is upregulated after treatment with prolactin (Fig. 2; Jabbour et al., 1999). The sites of expression of prolactin, prolactin receptor and IRF-1 in the human endometrium indicate that prolactin-mediates gene transcription in the glandular epithelial cells in a paracrine fashion. Decidual prolactin secreted by the stromal cells acts on its receptors in the glandular compartment to upregulate the expression of target genes such as IRF-1 (Fig. 3). The target genes for prolactin via IRF-1 in the human endometrium remain to be established. However, in other model systems, IRF-1 regulates the expression of a wide array of genes that are associated with cellular proliferation, growth inhibition and differentiation (reviewed in Yu-Lee, 1997). One potential target gene for prolactin-induced IRF-1 in the human endometrium is interferon $\beta$. Interferon $\beta$ is expressed in the human uterus and co-localizes with prolactin receptors in the glandular epithelial cells $(H$. N. Jabbour, unpublished). IRF-1 binds to the upstream regulatory region of the interferon $\beta$ gene (Miyamoto et al., 1988) and activates reporter plasmids with the interferon $\beta$ promoter (Harada et al., 1990).

\section{Potential function of prolactin in early pregnancy}

\section{Epithelial cell differentiation and implantation}

The temporal pattern of expression of prolactin receptors throughout the menstrual cycle indicates that prolactin plays a differentiative rather than a mitogenic role in the glandular epithelial cells. This is inferred from the absence of expression of the receptor during the proliferative phase 


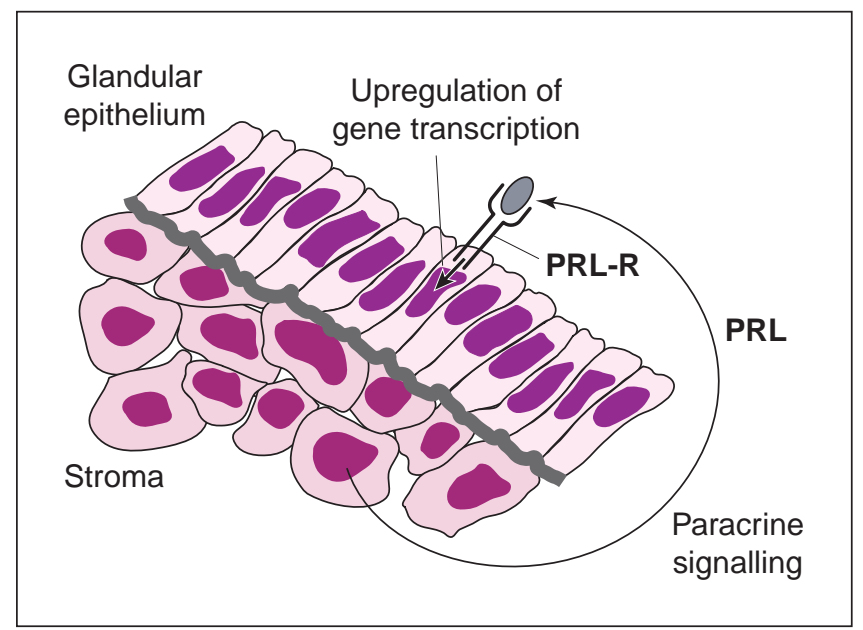

Fig. 3. Decidual prolactin (PRL) secreted by stromal cells mediates, via its membrane bound receptors (PRL-R), the transcription of genes in the glandular epithelial cells in a paracrine fashion.

of the menstrual cycle, the period during which the glandular epithelial cells are undergoing rapid mitogenesis. The abundant expression of prolactin and its receptor during the secretory phase implies that prolactin may be regulating the secretory function of the endometrial glands at the time of predicted conception and trophoblast implantation. A role for prolactin in implantation has been outlined in the prolactin and prolactin receptor knockout mouse (Horseman et al., 1997; Ormandy et al., 1997). Female mice with a null mutation for the prolactin and prolactin receptor are sterile and their uteri are refractory to implantation. However, the mechanism by which prolactin may influence implantation is not clear. Prolactin may regulate the expression or secretion of factors within the glandular compartment that may facilitate trophoblast cell adhesion and invasion of the endometrium. Prolactin influences the expression of a number of adhesion and proteolytic molecules (reviewed in Yu-Lee, 1997). Such molecules would facilitate trophoblast attachment followed by extracellular matrix degradation of the endometrium to facilitate trophoblast cell invasion (Starzyk et al., 1999).

\section{Regulation of trophoblast cell growth}

During early pregnancy, the invading trophoblast cells which originate from the proliferating tips of the anchoring villi differentiate to either mononucleated endovascular cells or multi-nucleated syncytiotrophoblast cells within the placental bed (Starzyk et al., 1999). The control of proliferation of the invading trophoblast cells is presumably one mechanism of regulating the degree of endometrial invasion. Under-invasion of trophoblast cells can lead to defective placentation and the failure to develop a normal uteroplacental blood supply, which culminate in clinical conditions such as pre-eclampsia during pregnancy. It is possible that prolactin regulates trophoblast cell function and the degree of invasion in the endometrium. The human placental tissue, and more specifically the syncytiotrophoblast cells, express both the long and intermediate forms of the prolactin receptor (Maaskant et al., 1996; Kline et al., 1999). The physiological significance of Coexpression of the two receptor isoforms in the placenta has not been elucidated. However, studies in vitro demonstrate that the long but not intermediate form of the human receptor induces a mitogenic signal in response to prolactin (Kline et al., 1999). Hence, the intermediate form of the receptor may act as a dominant negative receptor to control the mitogenic effect of prolactin mediated by the long receptor. It is also plausible that prolactin controls the growth of the trophoblast cells in the endometrium through expression of specific growth inhibition signals. One candidate molecule is interferon $\beta$, which is a known regulator of cell growth with antiproliferative activity (Meager, 1998).

\section{Angiogenesis}

Prolactin stimulates and inhibits angiogenesis: the intact prolactin molecule is angiogenic and its $\mathrm{N}$-terminal $16 \mathrm{kDa}$ fragment is anti-angiogenic (Struman et al., 1999). In addition, expression of the prolactin gene is detected in capillary endothelial cells, and prolactin acts in an autocrine-paracrine fashion to regulate cellular proliferation (Clapp et al., 1998). The opposite actions of the intact and $16 \mathrm{kDa}$ cleaved fragment are mediated by independent receptors rather than by competition for binding to the same receptor (Struman et al., 1999). Ligand binding and chemical crosslinking studies confirm that the $16 \mathrm{kDa}$ prolactin fragment but not the $23 \mathrm{kDa}$ prolactin binds to high affinity saturable sites in endothelial cell membranes, which are distinct in size from the cloned prolactin receptors (Clapp and Weiner, 1992). Moreover, the $16 \mathrm{kDa}$ prolactin fragment does not compete with the intact prolactin molecule for binding to the classical prolactin receptors (Struman et al., 1999). The angiogenic effect of prolactin on endothelial cells is mediated in part via the MAP kinase signalling pathway. Treatment of endothelial cells with intact $24 \mathrm{kDa}$ prolactin induces tyrosine phosphorylation and activation of MAP kinase. However, the 16 kDa prolactin fragment inhibits growth factor-induced MAP kinase phosphorylation (Struman et al., 1999).

In early pregnancy, placental development and establishment of maternal-fetal circulation is tightly controlled through the expression of angiogenic and anti-angiogenic factors. Impairment of placental development is associated with early pregnancy loss and is observed in pregnancies complicated with pre-eclampsia and intrauterine fetal retardation. In the pregnant uterus, blood vessel development in the placenta may be promoted by decidual prolactin via its classical receptors: both the long and intermediate forms of the receptor are highly expressed in placental tissue (Kline et al., 1999). Whether the $16 \mathrm{kDa}$ 
prolactin fragment and its receptor are produced in the pregnant uterus to counter-balance the degree of vascularization by the intact prolactin molecule remains to be elucidated. However, a potential role for $16 \mathrm{kDa}$ prolactin in the pregnant uterus is supported by observations that cathepsin $\mathrm{D}$, the enzyme that cleaves intact prolactin into its $16 \mathrm{kDa}$ fragment, is produced in the deciduo-placental interface (Earl et al., 1989; Fig. 4).

\section{Immune regulation}

A role for prolactin in immune regulation is well documented (reviewed in Yu-Lee, 1997). Prolactin and prolactin receptor expression have been described in a number of haematopoietic cells in the peripheral circulation (Pellegrini et al., 1992), indicating that prolactin acts in an autocrineparacrine fashion to influence immune cell proliferation and function. Moreover, prolactin receptor expression has been reported in haematopoietic cells (Jabbour et al., 1998) within the endometrium and this is not surprising since these cells are likely to be recruited from the peripheral circulation. However, these cells may undergo in situ proliferation and differentiation. Endometrial haematopoietic cells increase in number during the secretory phase of the menstrual cycle (Klentzeris et al., 1992) and have different phenotypic characteristics to haematopoietic cells within the peripheral circulation (King et al., 1991). Prolactin has marked mitogenic and anti-apoptotic effects on cells of the haematopoietic system as clearly demonstrated in the pre-T lymphoma Nb2 cells. Moreover, prolactin is associated with lymphoid cell differentiation (reviewed in Yu-Lee, 1997). Haematopoietic cell proliferation and differentiation during the secretory phase of the menstrual cycle and early pregnancy may play a vital role in the control of implantation and establishment of vasculature and blood supply at the fetoplacental unit (King and Loke, 1990). The local signals responsible for these uterine immune cell modifications may be orchestrated by prolactin, which is expressed at increasing concentrations by the pseudodecidualized and decidualized endometrium during the secretory phase of the menstrual cycle and early pregnancy.

\section{Conclusions}

The temporal pattern and sites of expression of prolactin and its receptor in the pregnant and non-pregnant endometrium indicate a crucial role for the cytokine in establishment and maintenance of pregnancy. Recent data demonstrating the expression of different isoforms of the receptor with differential signalling pathways in the placenta indicate a diverse function for the cytokine within target cells. Future studies outlining the target genes of prolactin in the different cellular components within the deciduo-placental interface may provide insight into the exact role of prolactin in the pregnant human endometrium. Moreover, comparative studies outline a similar function of prolactin in other primate species. These studies may provide a useful model for human pregnancy and assist further in understanding the role of prolactin and its different receptor isoforms in implantation and the successful establishment and maintenance of normal pregnancy.

The authors acknowledge the expert pictorial services of Ted Pinner and Tom McFetters.

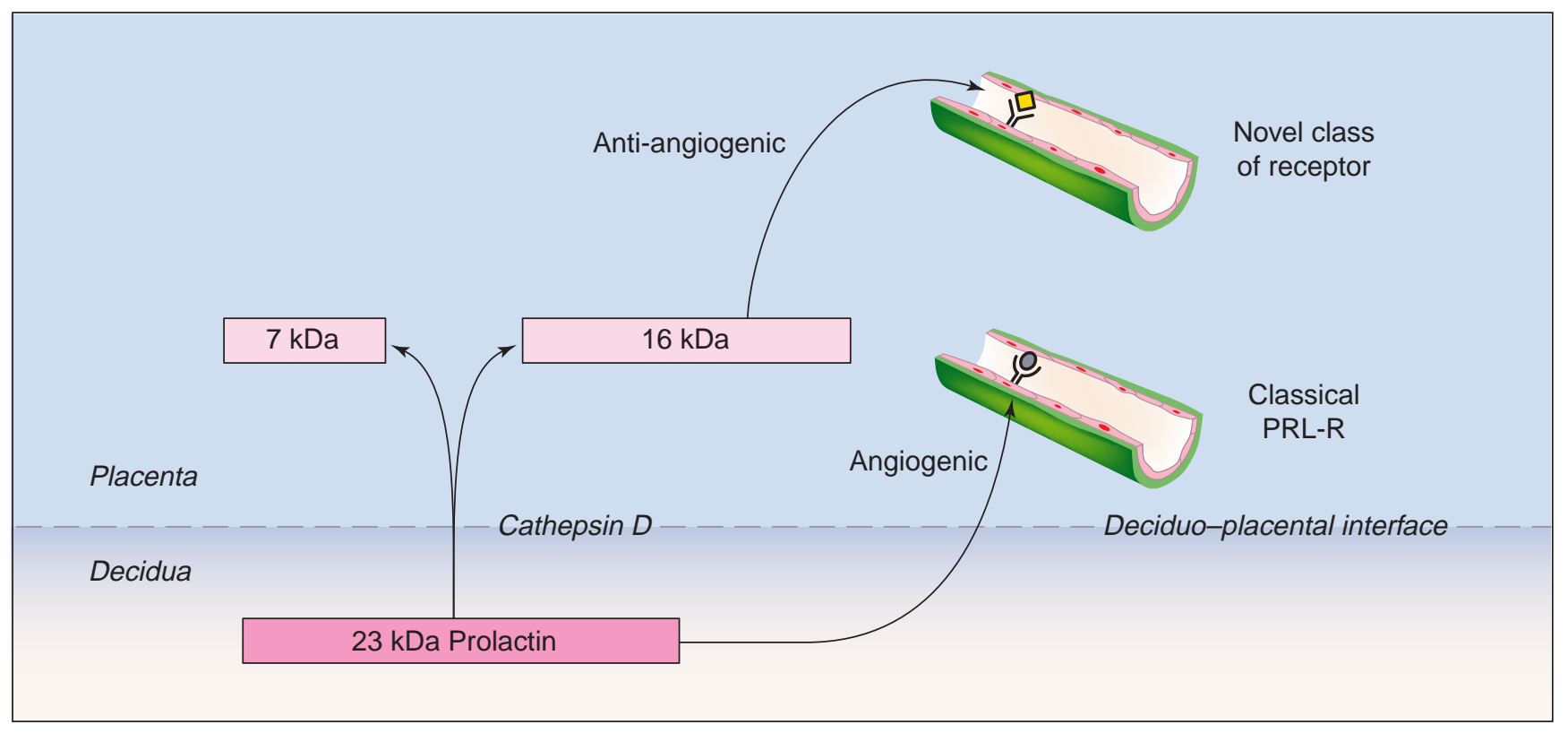

Fig. 4. Potential role of prolactin in angiogenesis in early pregnancy. Decidual $23 \mathrm{kDa}$ prolactin may act via the classic prolactin receptors (PRL-R) to promote angiogenesis in early pregnancy. Moreover, $23 \mathrm{kDa}$ prolactin can be cleaved by cathepsin D in the deciduo-placental interface to $16 \mathrm{kDa}$ prolactin, which is reputed to have an anti-angiogenic effect via a novel class of prolactin receptors. 


\section{References}

Key references are identified by askerisks.

Berlanga JJ, Garcia-Ruiz JP, Perrot-Applanat M, Kelly PA and Edery M (1997) The short form of the prolactin (PRL) receptor silences PRL induction of the $\beta$-casein gene promoter Molecular Endocrinology 11 1449-1457

Bignon C, Binart N, Ormandy C, Schuler LA, Kelly PA and Diiane J (1997) Long and short forms of the ovine prolactin receptor: cDNA cloning and genomic analysis reveal that the two forms arise by different alternative splicing mechanisms in ruminants and in rodents Journal of Molecular Endocrinology 19 109-120

Brosens JJ, Hayashi N and White JO (1999) Progesterone receptor regulates decidual prolactin expression in differentiating human endometrial stromal cells Endocrinology 140 4809-4820

Clapp C and Weiner RI (1992) A specific, high affinity, saturable binding site for the 16-kilodalton fragment of prolactin on capillary endothelial cells Endocrinology 130 1380-1386

Clapp C, Lopez-Gómez FJ, Nava G et al. (1998) Expression of prolactin mRNA and of prolactin-like proteins in endothelial cells: evidence for autocrine effects Journal of Endocrinology 158 137-144

*Critchley H and Healy D (1998) Effects of oestrogen and progesterone on the endometrium. In Estrogens and Progesterons in Clinical Practice pp 145-161 Eds R Jansens, R Lobo and M Whitehead. Churchill Livingstone, London

Critchley HO, Wang H, Jones RL, Kelly RW, Drudy TA, Gebbie AE, Buckley CH, McNeilly AS and Glasier AF (1998) Morphological and functional features of endometrial decidualization following long-term intrauterine levonorgestrel delivery Human Reproduction 13 1218-1224

Dalrymple A and Jabbour HN (2000) Localization and signaling of the prolactin receptor in the uterus of the common marmoset monkey Journal of Clinical Endocrinology and Metabolism 85 1711-1718

Daly DC, Maslar IA and Riddick DH (1983) Prolactin production during in vitro decidualization of proliferative endometrium American Journal of Obstetrics and Gynecology 145 672-678

Das R and Vonderhaar BK (1995) Transduction of prolactin's (PRL) growth signal through both long and short forms of the PRL receptor Molecular Endocrinology 9 1750-1759

Earl U, Morrison L, Gray C and Bulmer JN (1989) Proteinase and proteinase inhibitor localization in the human placenta International Journal of Gynecological Pathology 8 114-124

Enmark E, Pelto-Huikko M, Grandien K, Lagercrantz S, Lagercrantz J, Fried G, Nordenskjold M and Gustafsson JA (1997) Human estrogen receptor beta-gene structure, chromosomal localization, and expression pattern Journal of Clinical Endocrinology and Metabolism 82 4258-4265

Ferrari A, Petraglia F and Gurpide E (1995) Corticotropin releasing factor decidualizes human endometrial stromal cells in vitro. Interaction with progestin Journal of Steroid Biochemistry and Molecular Biology 54 251-255

Frank GR, Brar AK, Cedars MI and Handwerger S (1994) Prostaglandin E2 enhances human endometrial stromal cell differentiation Endocrinology $134258-263$

Frasor J, Gaspar CA, Donnelly KM, Gibori G and Fazleabas AT (1999) Expression of prolactin and its receptor in the baboon uterus during the menstrual cycle and pregnancy Journal of Clinical Endocrinology and Metabolism 84 3344-3350

Gellersen B, DiMattia GE, Friesen HG and Bohnet HG (1989) Prolactin (PRL) mRNA from human decidua differs from pituitary PRL mRNA but resembles the IM-9-P3 lymphoblast PRL transcript Molecular and Cellular Endocrinology 64 127-130

Gellersen B, Kempf R, Telgmann R and DiMattia GE (1994) Nonpituitary human prolactin gene transcription is independent of Pit-1 and differentially controlled in lymphocytes and in endometrial stroma Molecular Endocrinology 8 356-373

Harada H, Willison K, Sakakibara J, Miyamoto M, Fujita T and Taniguchi T (1990) Absence of type I IFN system in EC cells: transcriptional activator (IRF-1) and repressor (IRF-2) genes are developmentally regulated Cell 63 303-312
Horseman ND, Zhao W, Montecino-Rodriguez E, Tanaka M, Nakashima K, Engle SJ, Smith F, Markoff E and Dorshkind K (1997) Defective mammopoiesis, but normal hematopoiesis, in mice with a targeted disruption of the prolactin gene EMBO Journal 16 6926-6935

Huang JR, Tseng L, Bischof $\mathbf{P}$ and Janne OA (1987) Regulation of prolactin production by progestin, estrogen, and relaxin in human endometrial stromal cells Endocrinology 121 2011-2017

Ingraham HA, Flynn SE, Voss JW, Albert VR, Kapiloff MS, Wilson L and Rosenfeld MG (1990) The POU-specific domain of Pit-1 is essential for sequence-specific, high affinity DNA binding and DNA-dependent Pit1-Pit-1 interactions Cell 61 1021-1033

Irwin JC, Kirk D, King RJ, Quigley MM and Gwatkin RB (1989) Hormonal regulation of human endometrial stromal cells in culture: an in vitro model for decidualization Fertility and Sterility $\mathbf{5 2}$ 761-768

*Jabbour HN, Critchley HO and Boddy SC (1998) Expression of functional prolactin receptors in nonpregnant human endometrium: janus kinase-2, signal transducer and activator of transcription-1 (STAT1), and STAT5 proteins are phosphorylated after stimulation with prolactin Journal of Clinical Endocrinology and Metabolism 83 2545-2553

Jabbour HN, Critchley HO, Yu-Lee LY and Boddy SC (1999) Localization of interferon regulatory factor-1 (IRF-1) in nonpregnant human endometrium: expression of IRF-1 is up-regulated by prolactin during the secretory phase of the menstrual cycle Journal of Clinical Endocrinology and Metabolism 84 4260-4265

Jones RL, Critchley HOD, Brooks J, Jabbour HN and McNeilly AS (1998) Localisation and temporal pattern of expression of prolactin receptor in human endometrium Journal of Clinical Endocrinology and Metabolism 83 258-262

Kelly PA, Djiane J, Postel-Vinay MC and Edery M (1991) The prolactin/ growth hormone receptor family Endocrine Reviews 12 235-241

King A and Loke YW (1990) Uterine large granular lymphocytes: a possible role in embryonic implantation? American Journal of Obstetrics and Gynecology 162 308-310

King A, Balendran N, Wooding P, Carter NP and Loke YW (1991) CD3leukocytes present in the human uterus during early placentation: phenotypic and morphologic characterization of the CD56++ population Developmental Immunology 1 169-190

Klentzeris LD, Bulmer JN, Warren A, Morrison L, Li TC and Cooke ID (1992) Endometrial lymphoid tissue in the timed endometrial biopsy: morphometric and immunohistochemical aspects American Journal of Obstetrics and Gynecology 167 667-674

Kline JB, Roehrs H and Clevenger CV (1999) Functional characterization of the intermediate isoform of the human prolactin receptor Journal of Biological Chemistry 27435 461-35 468

Kuiper GG, Enmark E, Pelto-Huikko M, Nilsson S and Gustafsson JA (1996) Cloning of a novel receptor expressed in rat prostate and ovary Proceedings National Academy of Sciences USA 93 5925-5930

Lane B, Oxberry W, Mazella J and Tseng L (1994) Decidualization of human endometrial stromal cells in vitro: effects of progestin and relaxin on the ultrastructure and production of decidual secretory proteins Human Reproduction 9 259-266

Lessey BA, Killam AP, Metzger DA, Haney AF, Greene GL and McCarty KS, Jr (1988) Immunohistochemical analysis of human uterine estrogen and progesterone receptors throughout the menstrual cycle Journal of Clinical Endocrinology and Metabolism 67 334-340

Maaskant RA, Bogic LV, Gilger S, Kelly PA and Bryant-Greenwood GD (1996) The human prolactin receptor in the fetal membranes, decidua, and placenta Journal of Clinical Endocrinology and Metabolism $\mathbf{8 1}$ 396-405

Maslar IA and Ansbacher R (1986) Effects of progesterone on decidual prolactin production by organ cultures of human endometrium Endocrinology 118 2102-2108

Maslar IA and Riddick DH (1979) Prolactin production by human endometrium during the normal menstrual cycle American Journal of Obstetrics and Gynecology 135 751-754

Meager A (1998) Interferons alpha, beta and omega. In Cytokines pp 361-389 Eds AR Mire-Sluis and R Thorpe. Academic Press, San Diego, CA 
Miller JF, Williamson E, Glue J, Gordon YB, Grudzinskas JG and Sykes A (1980) Fetal loss after implantation. A prospective study Lancet 2 554-556

Miyamoto M, Fujita T, Kimura $Y$, Maruyama M, Harada H, Sudo $Y$, Miyata T and Taniguchi T (1988) Regulated expression of a gene encoding a nuclear factor, IRF-1, that specifically binds to IFN-beta gene regulatory elements Cell $\mathbf{5 4}$ 903-913

Nemansky M, Moy E, Lyons CD, Yu I and Blithe DL (1998) Human endometrial stromal cells generate uncombined alpha-subunit from human chorionic gonadotropin, which can synergize with progesterone to induce decidualization Journal of Clinical Endocrinology and Metabolism 83 575-581

Ormandy CJ, Camus A, Barra J et al. (1997) Null mutation of the prolactin receptor gene produces multiple reproductive defects in the mouse Genes and Development 11 167-178

*Osteen KG (1999) The endocrinology of uterine decidualisation. In Endocrinology of Pregnancy pp 541-553 Ed. FW Bazer. Human Press Inc., New Jersey

Pellegrini I, Lebrun JJ, Ali S and Kelly PA (1992) Expression of prolactin and its receptor in human lymphoid cells Molecular Endocrinology $\mathbf{6}$ 1023-1031

Pierro E, Andreani CL, Lazzarin N, Minici F, Apa R, Miceli F, Ayala G, Mancuso S and Lanzone A (1999) Effect of anticardiolipin antibodies on prolactin and insulin-like growth factor binding protein-1 production by human decidual cells American Journal of Reproductive Immunology 41 209-216

Pohnke Y, Kempf R and Gellersen B (1999) CCAAT/enhancer-binding proteins are mediators in the protein kinase A-dependent activation of the decidual prolactin promoter Journal of Biological Chemistry 274 24 808-24 818

Reis FM, Maia AL, Ribeiro MF and Spritzer PM (1999) Progestin modulation of c-fos and prolactin gene expression in the human endometrium Fertility and Sterility 71 1125-1132

Rhodes SJ, DiMattia GE and Rosenfeld MG (1994) Transcriptional mechanisms in anterior pituitary cell differentiation Current Opinion in Genetics and Development 4 709-717

Rosenberg M, Mazella J and Tseng L (1991) Relative potency of relaxin, insulin-like growth factors, and insulin on the prolactin production in progestin-primed human endometrial stromal cells in long-term culture Annals New York Academy of Sciences 622 138-144

Seth A, Gonzalez FA, Gupta S, Raden DL and Davis RJ (1992) Signal transduction within the nucleus by mitogen-activated protein kinase Journal of Biological Chemistry 26724 796-24 804

Starzyk KA, Pijnenborg R and Salafia CM (1999) Decidual and vascular pathophysiology in pregnancy compromise Seminars in Reproductive Endocrinology 17 63-72

*Struman I, Bentzien F, Lee H, Mainfroid V, D'Angelo G, Goffin V, Weiner RI and Martial JA (1999) Opposing actions of intact and $\mathrm{N}$-terminal fragments of the human prolactin/growth hormone family members on angiogenesis: an efficient mechanism for the regulation of angiogenesis Proceedings National Academy of Sciences USA 96 1246-1251

Takahashi H, Nabeshima Y, Ogata K and Takeuchi S (1984) Molecular cloning and nucleotide sequence of DNA complementary to human decidual prolactin mRNA Journal of Biochemistry (Tokyo) 95 1491-1499

Telgmann R and Gellersen B (1998) Marker genes of decidualization: activation of the decidual prolactin gene Human Reproduction Update 4 472-479

Telgmann R, Maronde E, Tasken K and Gellersen B (1997) Activated protein kinase $A$ is required for differentiation-dependent transcription of the decidual prolactin gene in human endometrial stromal cells Endocrinology 138 929-937

Tomita K, McCoshen JA, Fernandez CS and Tyson JE (1982) Immunologic and biologic characteristics of human decidual prolactin American Journal of Obstetrics and Gynecology 142 420-426

Tung L, Mohamed MK, Hoeffler JP, Takimoto GS and Horwitz KB (1993) Antagonist-occupied human progesterone B-receptors activate transcription without binding to progesterone response elements and are dominantly inhibited by A-receptors Molecular Endocrinology 7 1256-1265

Wang H, Critchley HO, Kelly RW, Shen D and Baird DT (1998) Progesterone receptor subtype B is differentially regulated in human endometrial stroma Molecular Human Reproduction 4 407-412

Wang JD, Zhu JB, Shi WL and Zhu PD (1994) Immunocytochemical colocalization of progesterone receptor and prolactin in individual stromal cells of human decidua Journal of Clinical Endocrinology and Metabolism 79 293-297

Wilcox AJ, Weinberg CR, O'Connor JF, Baird DD, Schlatterer JP, Canfield RE, Armstrong EG and Nisula BC (1988) Incidence of early loss of pregnancy New England Journal of Medicine 319 189-194

Wu WX, Brooks J, Glasier AF and McNeilly AS (1995) The relationship between decidualisation and prolactin mRNA and production at different stages of human pregnancy Journal of Molecular Endocrinology 14 255-261

*Yu-Lee Ly (1997) Molecular actions of prolactin in the immune system Proceedings Society for Experimental Biology and Medicine 215 $35-52$ 